\title{
A AVALIAÇÃO COMO INSTRUMENTO DO PROCESSO DE ENSINO- APRENDIZAGEM
}

\author{
Michele da Rosa Scholant Simoes ${ }^{1}$
}

RESUMO: Este trabalho aborda a avaliação como ferramenta capaz de diagnosticar fragilidades do processo educativo, para que dessa forma seja possível redirecioná-lo, para uma transformação positiva. Para isso, buscou-se descrever os conceitos de avaliar, de avaliação, dos tipos de avaliação, das finalidades de avaliação, dos métodos de avaliação e o papel da avaliação na perspectiva do professor do ensino superior. O objetivo principal é uma reflexão sobre a avaliação educacional concentrada na avaliação da aprendizagem. Para o alcance do objetivo geral, outros objetivos específicos foram delineados, tendo em vista que estes favoreceriam a compreensão do assunto em questão: conceituar as concepções avaliativas segundo os fundamentos teóricos de vários autores; descrever e caracterizar os tipos de avaliação; determinar se os instrumentos avaliativos; descrever os quatro pilares da educação mundial. Questionou-se: Qual o papel da avaliação no processo de ensino-aprendizagem? A metodologia adotada foi de cunho qualitativo e foi baseada em estudos bibliográficos a partir de leituras em livros e artigos. O trabalho foi dividido em tópicos que foram abordados no decorrer do trabalho. Justifica-se a escolha pelo tema abordado por se tratar de assunto de grande importância e por ser um tema sempre atual, presente na sociedade, visto que a avaliação e suas práticas ocupam o centro das preocupações, tanto das instituições de ensino superior como do próprio Governo Federal. Conclui-se que, a reflexão da ação pedagógica assim como a busca da fundamentação teórica e prática devem ser uma constante no trabalho do educador, para possa redimensionar a sua atuação na melhoria do processo ensinoaprendizagem.

Palavras-chave: Avaliação da Aprendizagem. Educação. Ensino-Aprendizagem.

ABSTRACT: This work approaches the evaluation as a tool able to diagnose weaknesses of the educational process, so that it can be redirected to a positive transformation. The purpose of this study was to describe the concepts of evaluation, evaluation, types of evaluation, assessment purposes, evaluation methods and the role of evaluation in the perspective of higher education teachers. The main objective is a reflection on the educational evaluation focused on the evaluation of learning. In order to reach the general objective, other specific objectives were outlined, since they would favor the understanding of the subject in question: to conceptualize the evaluation conceptions according to the theoretical foundations of several authors; Describe and characterize the types of evaluation; Determine whether the evaluation instruments; Describe the four pillars of world education. It was questioned: What is the role of evaluation in the teaching-learning process? The methodology adopted was of a qualitative nature and was based on bibliographic studies from reading books and articles. The work was divided into topics that were addressed in the course of the work. It is justifiable to choose the topic addressed because it is a matter of great importance and because it is an ever current topic present in society, since the evaluation and its practices occupy the center of the concerns, both of higher education institutions and of the institution itself Federal government. It is concluded that the reflection of the pedagogical action as well as the search for the theoretical and practical foundation must be a constant in the work of the educator, so as to be able to re-dimension its action in the improvement of the teachinglearning process.

Palavras-chave: Learning Assessment. Education. Teaching-Learning.

\footnotetext{
${ }^{\mathrm{I}}$ Médica Veterinária - Professora Centro Universitário Ideau Bagé. Mestre em Melhoramento Animal. Doutoranda em Melhoramento Animal
} 


\section{INTRODUÇÃO}

O presente trabalho aborda a avaliação, um assunto que vem ganhando cada vez mais espaço para discussão, visto representar parte fundamental para que o processo de ensino e aprendizagem se concretize, quando tratamos de questões educacionais.

A avaliação se caracteriza por ser um dos pontos principais para que a prática pedagógica possa ser usada de forma eficiente de diversas formas e finalidades, nos vários níveis do sistema educacional.

São inúmeros os conceitos formais de avaliação, cada um deles mostrando um enfoque diferente e deixando claro sua complexidade, sendo que a avaliação da aprendizagem é a mais estudada, ocupando papel fundamental nas escolas e universidades, podendo contribuir ou não para a aprendizagem, dependendo de como é utilizada.

O aluno, em uma avaliação, deve ser levado a pensar, a buscar novosrecursos, com finalidade de chegar a um denominador comum e atingir o conhecimento, sendo que para que isso venha a ocorrer a figurara do professor é parte fundamental.

Os professores são, necessariamente, profissionais altamente especializados e, por isso, têm que ter uma formação inicial e contínua sofisticada, profunda e abrangente para que possam responder à complexidade e às exigências do processo de ensino (FERNANDES, 2009).

O problema que orienta este artigo é qual o papel da avaliação no processo de ensino-aprendizagem?

$\mathrm{Na}$ tentativa de dar respostas a esse questionamento e com foco nos objetivos, a metodologia adotada nessa pesquisa é de cunho qualitativo e foi baseada em estudos bibliográficos a partir de leituras em livros e artigos científicos, teses e outros documentos referentes ao assunto abordado.

Optou-se por uma pesquisa de caráter exploratório por uma abordagem qualitativa, partindo de fontes bibliográficas, onde buscou-se na literatura documentos que aprimorassem as idéias sobre o tema proposto.

De acordo com Freitas (2002, p. 2I), “[...] a pesquisa qualitativa orientadapela perspectiva sócio-histórica: enfatiza [...] a compreensão dos fenômenos a partir de seu acontecer histórico, no qual o particular é considerado uma instância da totalidade social [...]" e pode interferir na apropriação do conhecimento.

Como procedimento técnico, utilizou-se a pesquisa bibliográfica, tendo como aporte 
teórico pensadores críticos, a exemplo de Luckesi (1999 e 2012), Hoffmann (2011 e 2012) e Frias e Takahashi (2012), que se constituíram em pilares para a elaboração deste estudo e ofereceram respaldo aos questionamentos suscitados.

Objetivo Geral deste artigo é refletir sobre a avaliação educacional concentrada na avaliação da aprendizagem e conceituar as concepções avaliativas segundo os fundamentos teóricos de vários autores, descrever e caracterizar os tipos de avaliação, determinar se os instrumentos avaliativos, descrever os quatro pilares da educação mundial.

\section{REFERENCIAL TEÓRICO}

Nesta seção, abordam-se conceitos que contextualizam e fundamentam o avaliar e a avaliação.

\section{I Avaliar}

Segundo Lima (2016, p. 86) do latim, “a + valere”, avaliar significa "dar valor a...”, atribuir valor ao objeto, conferir juízo de valor atribuindo qualidade do seu resultado.

Para Zenon e Freitas (2007) avaliar é um método para adquirir e processar evidências necessárias para melhorar a aprendizagem do aluno, um instrumento de prática educativa que permite estabelecer a eficácia das várias intervenções do professor, ajuda a esclarecer quais são as metas e os objetivos mais importantes da educação e determinar o grau em que os alunos evoluem para atingi-los.

Leitão (2013, p. 5) refere que "avaliar é proceder a uma análise daquilo que foi feito e considerar aquilo que pode ser feito para melhorar ou alterar o rumo de alguma coisa”.

Segundo os PCN's, avaliar significa:

Emitir em juízo de valor sobre a realidade que se questiona, seja propósito das exigências de uma ação que se projetou realizar sobre ela, seja a propósito de suas consequência (PCN, 1997, p. 86).

Conforme Luckesi (20II, p. 64). "o ato de avaliar se dedica a desvendar impasses e buscar soluções".

De acordo com Cavalcanti Neto e Aquino (2009, p. 4), “[...], avaliar é muito mais do que aplicar um teste, uma prova, fazer uma observação, saber se um aluno merece esta ou aquela nota, este ou aquele conceito”. Para esses autores, a avaliação vai além de um aspecto quantitativo e é muito mais do que aplicar uma prova e fazer uma observação. 
Afinal, "avaliar é um ato rigoroso de acompanhamento da aprendizagem".

Percebe-se que no ato de avaliar, existem dois pólos irredutíveis: o avaliado e o avaliador, que funcionam como o receptor e o que comunica. Para esta relação ser benéfica, tem de estar previamente estabelecido um sentido para a avaliação, ou seja, tanto um como outro, têm de saber o porquê de se estar a avaliar.

Luckesi (20II) afirma que para saber avaliar é preciso conhecer os conceitos teóricos sobre avaliação e o mais importante aprender a prática da avaliação, pois para saber conceitos teóricos é só buscar as fontes e estudar, mas a prática é algo mais complexo. Passar da teoria para a prática requer experimento, análise, compreensão e acima de tudo a busca de novas formas do saber fazer.

\subsection{AVALIAÇÃO - DISCUTINDO CONCEITOS}

De acordo com Sibila (2012, p. 32) "ao longo dos tempos, o significado atribuído à avaliação tem sido bastante diverso, considerando que cada momento e lugar suscitam diferentes formas de analisar a relação ensino/aprendizagem".

Para Sobrinho (2006, p. 95), o conceito de avaliação é globalizado:

A Avaliação não é um processo autolimitado, que basta em si mesmo. Visando tornar mais visível e compreensível o cotidiano de uma instituição, a avaliação ultrapassa os âmbitos mais restritos do objeto a avaliar e lança seus efeitos sobre o sistema de educação superior e suas funções relativamente à construção da sociedade. Ela ilumina e instrumentaliza as reformas educacionais, desde a mudança nos currículos, maneiras de organização de cursos e formas gerenciais, até novas estruturas do sistema. Em outras palavras, a avaliação está no centro do processo de reformas, no foco de competições institucionais, e só ela garante a sobrevivência do ensino de excelência buscado pelas sociedades contemporâneas.

Salinas (2004, p. II) acrescenta a respeito do conceito de avaliação que,

[...] é difícil, talvez porque, em algumas ocasiões, a complexidade da realidade, seus múltiplos reflexos e a distinta perspectiva na qual cada um de nós pode percebê-la, impedem a conceitualização precisa e de caráter universal.

Para Almeida, Peron e Desidério (2009, p. 7) “[...] a avaliação da aprendizagem possibilita a tomada de decisão e a melhoria da qualidade de ensino, informando as ações em desenvolvimento e a necessidade de regulações constantes".

Sousa (20II) aponta a avaliação sob o prisma analítico da ação educativa e do processo de aprendizagem: a avaliação deve ser entendida como um processo contínuo e sistemático, compreensivo, comparativo, cumulativo, informativo e global que permite avaliar o conhecimento do aluno, não podendo ser esporádica nem improvisada, devendo, 
ser constante e planejada fornecendo feedback e permitindo a recuperação imediata quando for necessária.

Cardoso e Gomes (2016, p. 28) ressaltam que a avaliação deve estar comprometida com a formação humana, contribuir no processo de construção da autonomia, da consciência e da cidadania passando pela produção de conhecimentodo aluno, fazendo com que compreenda o mundo em que vive para além de usufruir,conhecê-lo e transformá-lo.

A avaliação não deve priorizar apenas o resultado ou o processo, mas deve interrogar a relação ensino-aprendizagem e buscar identificar os conhecimentos construídos e as dificuldades de uma forma dialógica (CARDOSO E GOMES, 2016). Moretto (2008) aponta que (...) avaliar a aprendizagem, está profundamente relacionado com o processo de ensino e, portanto, deve ser conduzido como ummomento que o aluno aprende; chamado de "momento privilegiado" porque, o alunocoloca suas energias em busca de sucesso, normalmente associado a uma boanota. $O$ primeiro passo para a transformação é dar ao processo de avaliação umnovo sentido, isto é, transformá-lo em oportunidade para o aluno ler, refletir,relacionar, operar mentalmente e demonstrar que tem recursos para abordarsituações complexas. Em síntese, o aluno deverá demonstrar ter adquirido

competência como estudante.

De acordo com Romão (20II), avaliação é o processo de atribuição de símbolos, a fenômenos com o objetivo de caracterizar o valor do fenômeno, geralmente com referência a algum padrão de natureza social, cultural ou cientifica.

Segundo Sant'Anna (2010), a avaliação significa atribuir um valor a umadimensão mensurável do comportamento em relação a um padrão de natureza social ou cientifica, avaliação é o processo de delinear, obter e fornecer informações úteis para julgar decisões alternativas.

De maneira geral, segundo Barbosa (2012, p. 2), “o termo avaliação está relacionado aos atos de julgar, de dar valor, de formular concepções a respeito de atitudes, sujeitos e objetos a partir de critérios particulares e pré-determinados”.

Ao promover análise e diagnósticos durante o processo educativo, que envolva o professor e o aluno, a avaliação deixa de ser percebida como resultado e passa a ser um dos elementos do processo de aprendizagem autoral, criativa e significativa (CARDOSO e GOMES, 2016). 
A ação pedagógica pode ser entendida como uma totalidade que compreende o ensino, a aprendizagem e a avaliação. Sob esse aspecto, a avaliação é o componente que permeia os demais elementos, diagnosticando-os e reorientado-os (GRILLO; LIMA, 20Iоa), o que caracteriza a interdependência dessas grandezas e oseu caráter processual.

De acordo com Batista (2014) é possível situar a avaliação dentro de duas abordagens: a quantitativa, encarada em que expressam forte influência do rigor positivista; e a qualitativa, que se propõe a compreender e intervir na situação de modo mais adequado.

Como pode ser percebido ao utilizar a avaliação com a função de medir ou classificar, perde-se o princípio básico de sua função, causando uma forma de "descontinuidade, de fragmentação, de segmentação, ou seja, de parcelarização do conhecimento" (CARMINATTI; BORGES, 2012, p. 17I).

Segundo Freitas, Costa e Miranda (2014) a avaliação deve ser entendida como processo, como meio e não como fim.

\subsection{Tipos de avaliação de aprendizagem}

Segundo Silva Filho, Ferreira e Moreira (2012) podemos classificar a avaliação como sendo de três tipos: a diagnóstica, a formativa e a somativa. Luckesi (2006) lembra que foi o pesquisador Benjamin Bloom que utilizou, pela primeira vez, essas denominações, na década de 1970. A seguir descrevemos cada uma delas, caracterizando-as e diferenciando-as.

De acordo com Luckesi (2011, p. 277) a avaliação diagnóstica é o processo de qualificar a realidade por meio de sua observação, como base em seus dados relevantes, e, a seguir, pela qualificação que é obtida pela comparação da realidade descrita com um critério, assumindo como qualidade desejada. O diagnóstico, propriamente, configura e encerra o ato de avaliar em si.

A avaliação diagnóstica visa verificar a existência, ou ausência, de habilidades e conhecimentos pré-estabelecidos, esta é uma ação que inicia o processo avaliativo e verifica se os alunos dominam os pré-requisitos necessários para novas aprendizagens (FREITAS; COSTA E MIRANDA, 2014).

Com isso, queremos dizer que: 
de desenvolvimento do aluno, dando-lhe elementos para verificar oque aprendeu e como aprendeu. É uma etapa do processo educacional que tem por objetivo verificar em que medidas os conhecimentos anteriores ocorreram e o que se faz necessário planejar para selecionar as dificuldades encontradas (SANT'ANNA, 1998, p. 33).

Segundo Sant'Anna (2010) a avaliação formativa é realizada com a finalidade de informar $\mathrm{o}$ professor $\mathrm{e}$ o aluno sobre $\mathrm{o}$ resultado $\mathrm{da}$ aprendizagem, durante $\mathrm{o}$ desenvolvimento das atividades escolares. Localiza deficiências na organização do ensino e aprendizagem, de modo a possibilitar reformulações no mesmo e assegurar a alcance dos objetivos.

$\mathrm{O}$ ato de avaliar consiste tanto na trajetória de construção das aprendizagens e dos conhecimentos do educando, como também no trabalho do professor; por permitir analisar “[...], de maneira frequente e interativa, o progresso dos alunos, [...]” e, em consequência “[...] identificar o que eles aprenderam e o que ainda não aprenderam, para que venham a aprender e para que reorganizem o trabalhopedagógico" (VILLAS BOAS, 2006, p. 78).

Sobre a avaliação formativa, podemos dizer que:

A avaliação formativa buscaria, além disso, compreender o funcionamento cognitivo do aluno em face da tarefa proposta. Os dados de interesseprioritário são os que dizem respeitos as representações das tarefas explicitadas pelo aluno e as estratégias ou processos que ele utiliza para chegar a certos resultados. Os "erros" constituem objeto de estudo particular, visto que são reveladores da natureza das representações ou dasestratégias elaboradas por ele. A finalidade da recuperação pedagógica será ajudar o aluno a descobrir aspectos pertinentes da tarefa e comprometer-se na construção de uma estratégia mais adequada (SOUZA, 1998, p. 67).

A avaliação formativa é realizada ao longo do processo, é contínua, e dá parâmetros ao professor para verificar se os objetivos foram alcançados, podendo interferir no que pode estar comprometendo a aprendizagem; tornando possível constatar se os objetivos estabelecidos foram atingidos pelos alunos, como também levantar dados para que o professor possa realizar um trabalho de recuperação e aperfeiçoar seus procedimentos (HAYDT, 2008).

De acordo com Sant'Anna (2010, p. 35) a avaliação somativa têm como função classificar os alunos ao final da unidade semestre ou ano letivo, segundo níveis de aproveitamento apresentados. Objetiva avaliar de maneira geral o grau em que os resultados mais amplos têm sido alcançados ao longo e ao final de um curso.

Kraemer (20II) explica: “a avaliação somativa pretende ajuizar do progresso realizado pelo aluno no final de uma unidade de aprendizagem, e aferir resultados já colhidos por avaliações do tipo formativa e obter indicadores que permitem aperfeiçoar o 
processo $[\ldots] ”$.

A avaliação somativa visa classificar os resultados da aprendizagemalcançados pelos alunos ao final do processo tendo a função de classificar o aluno e quantificar este processo avaliativo (HAYDT, 2008).

A avaliação somativa:

\begin{abstract}
Supõe uma comparação, pois o aluno é classificado segundo o nível de aproveitamento e rendimento alcançado, geralmente em comparação com os demais colegas, isto é, com o grupo classe. A ênfase no aspecto comparativo é próprio da escola tradicional. É com esse propósito que é utilizada a avalição somativa, com função classificatória, pois ela consiste em classificar os resultados da aprendizagem alcançados pelos alunos ao final de um semestre, ano ou curso, de acordo com os níveis de aproveitamento preestabelecidos. Portanto, consiste em atribuir ao aluno uma nota ou conceito final para fins de promoção (HAYDT, I991, p. 25-26).
\end{abstract}

Segundo Alves e Resende (2014) essa concepção de avaliação, seja ela diagnóstica, formativa ou somativa, busca realizar um acompanhamento, em todos os momentos do processo de aprendizado do aluno, a fim de auxiliá-lo em suas possíveis dificuldades, bem como acompanhar seus avanços.

\title{
2.2.2 Finalidades da avaliação
}

Segundo Filho, Ferreira e Moreira (2012, p. 7) "para que a avaliação adquira a importância que realmente tem no processo de ensino aprendizagem, é necessário um conhecimento mais aprofundado e seguro das dificuldades de aprendizagem dosalunos".

O professor não deve permanecer alheio a esta deficiência, pois ninguém melhor do que ele pode emitir um juízo de conjunto, a respeito do rendimento escolar de cada aluno. Se o professor é um educador, a avaliação dos alunos faz parte integrante de suas funções, visto que é fundamental a interação ente o educador e o educando, pois isso favorece, estimula, dirige, incentiva, impulsiona o processo de ensino-aprendizagem.

Malheiros (2012, p. 25) enfatiza que, "na pedagogia tradicional, ensinar é transmitir conteúdos e aprender é ser capaz de reproduzi-los"

A avaliação leva o professor a criar novos elementos para uma reflexão contínua sobre sua prática, criação de novos instrumentos, ter consciência de conteúdos e metodologias que devem ser usados, se necessário, revistos, refletir sobre estes instrumentos e adequá-los para o processo de aprendizagem individual ou de todo o grupo (CARDOSO e GOMES, 2016, p. 33).

É por meio das metodologias e dos processos avaliativos utilizados que o professor 
irá participar da reprodução ou transformação da sociedade na qual estamos inseridos, podendo formar, ou não, sujeitos críticos e emancipados paraque possam nela conviver com equidade (SANTOS e VARELA, 2007).

\subsubsection{Métodos de Avaliação}

Os instrumentos avaliativos adotados nas instituições educacionais dizem muito sobre a proposta educacional, a sua visão de educação e sobre a didática do professor, bem como suas raízes filosóficas e pedagógicas (LIMA, 2016).

São muitos os instrumentos avaliativos, por isso, vamos citar alguns deles, sendo os mais utilizados no contexto do Ensino Superior:

- Prova: verificação de domínio de conteúdo. As provas (testes ou exames) podem ser dissertativas - constituída de várias perguntas com enunciados que abordam temas distintos, que devem ser respondidas pelo aluno; e a prova objetiva consiste em perguntas com alternativas, onde o aluno assinala a resposta de acordo com o enunciado da questão (LIBÂNEO, 1994; FERREIRA, 2008);

- Relatório: exposição de dados, por escrito, constado a descrição do objeto de estudo e, se for o caso, a análise crítica sobre os dados;

- Memorial reflexivo: exposição escrita de caráter subjetivo, cujo objeto pode sermemória de vivência acompanhada de análise crítica ou exposição de uma situação vivenciada;

- Portfólio: “[...] coleção de trabalhos e atividades produzidos pelos alunos, adequadamente organizadas, que revela, com o passar do tempo, os diversos aspectos do crescimento e do desenvolvimento de cada um em particular" (RIBAS, 2007, p.158);

- Projeto de ação didática: “[...] desenvolve capacidades de pesquisa na medida em que incita a observar, a recorrer às técnicas diversificadas - entrevista, questionário, trabalho em grupo, exposição dialogada, observação, visitas, [...] para levantar indagações, desenvolver estratégias, descobrir, inventar [...]” (VEIGA, 2006, p. 76)

- Estudo dirigido: apresentação do roteiro dirigido/ proposta com questões para serem respondidas pelo aluno;

- Estudo de caso: análise minuciosa e objetiva de uma situação real que necessita 
ser investigada e é desafiadora para os envolvidos.

\subsection{O PAPEL DA AVALIAÇÃO NA PERSPECTIVA DO PROFESSOR DO ENSINO SUPERIOR}

Os mais recentes paradigmas da avaliação a concebem como parte do processo de ensino e aprendizagem, sendo realizada de forma contínua, cumulativa e sistemática na escola com objetivo de diagnosticar a situação de aprendizagem decada aluno em relação à programação curricular (HAMZE, 2010).

O papel da avaliação é singular no processo de ensino-aprendizagem por fornecer um feedback ao professor, pois permite “[...], compreender a finalidade dessa prática a serviço da aprendizagem, da melhoria da ação pedagógica, visando à promoção moral e intelectual dos alunos" (HOFFMANN, 20II, p.I8).

Para Ponta Grossa (2003, p. 123):

[...] a avaliação é um processo contínuo, diagnóstico; a avaliação deve apontar avanços e dificuldades de cada aluno; a avaliação não está desvinculada do processo ensino-aprendizagem; a aprendizagem pode ser mais difícil se não considerarmos a história do aluno; a aprendizagem dos conteúdos não se dá apenas em sala de aula, a partir da relação professor- aluno, mas também através do exercício social do conhecimento, nas relações sociais intra e extraclasse.

A ênfase na aprendizagem traz para os professores a tarefa de ajudar o aluno a aprender, de internalizar uma postura questionadora, crítica e permanentemente aberta às mudanças culturais, científicas e tecnológicas (SCHERER et al., 2009, p. 1420).

Em relação à educação superior, são poucas as pesquisas e elas indicam que a avaliação da aprendizagem se caracteriza, predominantemente, como somativa e classificatória (CHAVES, 2004), seguindo assim o paradigma quantitativo.

Se o objetivo máximo da docência é a aprendizagem do aluno, éimprescindível que a formação do professor universitário contemple a preparação pedagógica, de modo que se compreenda o processo de ensino-aprendizagem e o que realmente significa aprender, tanto do ponto de vista individual quanto coletivo (COSTA, 2008, p. 47).

Castanheira e Ceroni (2008) ressaltam que, cabe ao docente participar com idéias e ações na transformação da gestão (nas dimensões didático pedagógicas e comunitárias), da organização curricular, dos projetos educacionais e sociais.

Para esses mesmos autores (p. II 8 ), os pressupostos do ensino e da aprendizagem na universidade, apresentam os seguintes compromissos: organizar e oferecer um conjunto de conhecimentos, habilidades e atitudes que assegurem, aos estudantes, aprendizagem nos 
campos científico, pessoal e profissional; incentivar o comprometimento com as questões culturais e sociais, de forma crítica e autônoma, e com a produção de novos conhecimentos; considerar o processo de ensinar e aprender como atividade integrada à investigação; desenvolver a capacidade de investigação, ação-reflexão ação; criar e recriar situações de aprendizagem.

Anastasiou e Alves (2003), indicam quatro competências que o professor deve ter: competência pessoal (aprender a ser); competência relacional (aprender a conviver); competência produtiva (aprender a fazer); competência cognitiva (aprender a conhecer), que correspondem aos quatro pilares da Educação, apontados por Delors (1998), que são:

- Aprender a conhecer: Adquirir as competências necessárias para a compreensão. Destacamse as habilidades para construir conhecimentos e exercitar o pensamento. Assim, o aluno será capaz de selecionar informações com significado para sua realidade; - Aprender a fazer: Formar-se para o mundo do trabalho. Destacam-se a aplicação de conhecimentos significativos ao trabalho e o estímulo à criatividade; - Aprender a conviver: Descobrir o outro e identificar objetivos comuns. Destacam-se o autoconhecimento, a auto-estima, a solidariedade e a compreensão;

- Aprender a ser: Elaborar pensamentos autônomos e críticos. Destaca-se a ideia depreparar o ser humano inteiramente - espírito e corpo, inteligência e sensibilidade, sentido estético e responsabilidade pessoal, ética e espiritualidade (SOUZA e OKÇANA, 2010).

Segundo Castro e Carvalho (2006), os professores devem adotar uma postura em relação aos resultados da avaliação atribuindo aos alunos ou ao ensino os respectivos resultados, sejam negativos ou positivos. O professor deve preparar instrumentos coerentes com os objetivos propostos em seu planejamento curricular, podem utilizar instrumentos e recursos similares, porém de modos variados (ESTEBAN 2006; KRASILCHIK 2008).

$\mathrm{Na}$ educação de nível superior segundo Gil (201I) requer-se um professor capaz de gerar sua própria formação contínua, compartilhando a informação e conhecimento. Que ultrapasse a visão de formação direcionada apenas para o sistema, fundamentando suas convicções em três dimensões básicas: a pessoal, a profissional e a organizacional, que constituem a trilogia da formação continua: produzir a vida, a profissão e a escola em todo o contexto de aprendizado e numa linha continua e via dupla na relação professor-aluno, 


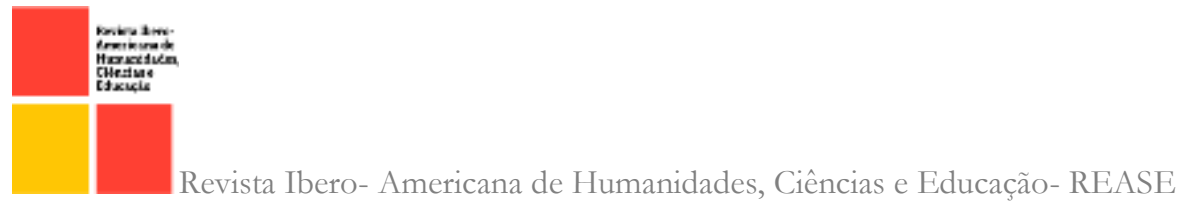

tendo como uma tríade, a organização educacional deve manter a relação de comunicação flexiva.

A avaliação da aprendizagem é uma das dimensões mais exigentes do complexo processo educativo. Igualmente para o professor, a avaliação da aprendizagem é de reconhecida utilidade, na medida em que permite a reflexão sobre a prática - o exame da coerência entre os objetivos buscados, os procedimentos de ensino utilizados e os resultados obtidos - e orienta a tomada de decisões pertinentes para a continuidade do ensino (GRILLO; GESSINGER e FREITAS et al., 2010, p. 17)

O professor aprende com as aprendizagens dos alunos: a forma como eles compreende ou não as explicações, a lógica dos seus acertos ou erros, o que não ficou claro e o que é preciso melhorar ou reformular; os alunos aprendem com os resultados da avaliação: compreendendo seus erros, buscando acertos, assumindo- se como protagonistas da sua aprendizagem (GRILLO; GESSINGER e FREITAS et al., 2010, p. 20)

\section{DISCUSSÃO}

Segundo Silva Filho; Ferreira e Moreira (2012), durante muito tempo, a avaliação, foi uma questão de notas, de quantificação do saber realizada através de provas ou exames; quem tirava as melhores notas era considerado como "melhor aluno", e quem tirava notas mais baixas era ridicularizado pela turma, chamado até de "burro", nada sendo feito para mudar essa realidade, visto que a avaliação não era tida como um aspecto de seu desenvolvimento.

A dificuldade que o professor possa encontrar em diferenciar a avaliação da aprendizagem de formas de testar e medir, talvez possa ser interpretada a partir de sua vida escolar e experiências formativas. Como aluno foi avaliado, como formandoaprendeu a avaliar dessa forma e como profissional realiza da mesma forma que a avaliação da aprendizagem esteve presente em sua trajetória de vida escolar e profissional (CARDOSO e GOMES, 2016, p. 3i).

Para Hadji (200I) e Chueiri (2008), a avaliação reduzida a uma perspectiva de medir desempenhos, tem a função de atribuir uma nota ao aluno, por meio "[...] de instrumentos avaliativos, tais como provas, dissertações, questionamentos orais, estudos de caso, entre outros, [...]” (GÓIS; BARBOSA, 2oro, p. II7).

Diante das diversas funções da avaliação, segundo Oliveira e Chadwiick(2007) e 


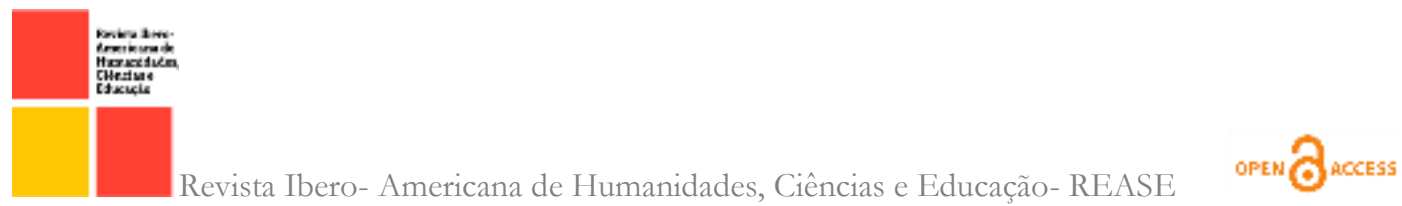

Kbrasilchik (2008), surgiu a necessidade de cautela no momento de decidir sobre a escolha, construção e aplicação dos instrumentos de verificação do aprendizado alcançado durante o processo avaliativo, visto que a avaliação quando colocada como parte, integrante do processo educativo, oferece subsídios para a ação-reflexão-ação frente às práticas pedagógicas, metodológicas e curriculares.

Segundo Carminatti e Borges (2012) a avaliação não deve ser percebida como um apêndice do processo de ensino-aprendizagem, ela deve ser entendida e utilizada de maneira a estar apropriada pelo processo, como algo integrado, do qual se sabe o verdadeiro propósito.

Moretto (2008) destaca que o que os professores podem avaliar pelas provas é a performance do aluno, obtendo assim um indicador de sua competência, utilizando diversos instrumentos de avaliação da aprendizagem para poder julgar a possível competência do aluno numa situação específica. Isso exige pesquisar formas avaliatórias que contemplem conjuntamente aspectos do processo e dos resultados, que permitam ao professor indicações a respeito de como lidar com aturma, escolhendo o que avaliar, quando avaliar e quem avaliar.

Libâneo et al. (2003) indicam como necessárias as seguintes ações: formaçãode uma boa equipe de trabalho; construção de uma comunidade democrática deaprendizagem; promoção de ações de desenvolvimento profissional; envolvimentodos alunos em processos de solução de problemas e de tomada de decisões;fortalecimento de formas de comunicação e de difusão de informações, entre outros.

De acordo com Cardoso e Gomes (2016, p. 33), "a avaliação leva o professor a criar novos elementos para uma reflexão contínua sobre sua prática, criação de novos instrumentos, ter consciência de conteúdos e metodologias que devem ser usados", se necessário, revistos, refletir sobre estes instrumentos e adequá-los para o processo de aprendizagem individual ou de todo o grupo. O que avaliar depende daquilo que se quer saber. O que se quer saber, por sua vez, depende das experiências e das informações prévias, sobretudo das suspeitas que o professor ou a escola desenvolveu a respeito do estado do conhecimento dos alunos.

\section{CONSIDERAÇÕES FINAIS}

A avaliação do processo de ensino e aprendizagem ganhou na atualidade espaço 
muito amplo nos processos de ensino, sendo realizada de forma contínua, cumulativa e sistemática, com o objetivo de diagnosticar a situação de aprendizagem de cada aluno, não devendo priorizar apenas o resultado ou o processo, mas como prática de investigação, interrogando a relação ensino aprendizagem e buscando identificar os conhecimentos construídos e as dificuldades de uma forma dialógica.

Este estudo fundamentou-se em uma revisão teórica dos mais diferentes conceitos de avaliação, tendo como base autores referenciados, em obras que elucidam o que se entende por avaliação e na reflexão sobre o que é considerado importante na implantação de processos avaliativos, das atividades que contribuem para a formação do docente de ensino superior, bem como a discussão de uma metodologia para a obtenção de dados e sua análise, visando a tomada correta de decisão.

O comprometimento com a formação do aluno passa, por uma avaliação que contemple a multiplicidade das dimensões de características subjetivas que tangenciam o processo de produção do conhecimento. Sendo assim, a avaliaçãonão pode ser entendida como um momento final do processo, mas estar presenteem todas as etapas do mesmo e funcionar como meio auxiliador da aprendizagem escolar.

Os métodos avaliativos são de suma importância no processo de ensinoaprendizagem. Como pode ser observado, o tema avaliação, se faz presente em todos os momentos da vida e da sociedade contemporânea na qual a avaliação de aprendizagem se apresenta muito mais sob uma abordagem qualitativa do que quantitativa.

Conclui-se que, a reflexão da ação pedagógica assim como a busca da fundamentação teórica e prática devem ser uma constante no trabalho do educador, para possa redimensionar a sua atuação na melhoria do processo ensino- aprendizagem. Nesse sentido a avaliação não pode ser entendida como um momento final, devendo estar presente em todas as etapas do processo e funcionar como meio auxiliador da aprendizagem escolar.

\section{REFERÊNCIAS}

ALMEIDA, Marlisa Bernardi de; PERON, Luciana Del Castanhel; DESIDÉRIO, Ricardo. Concepções de avaliação de professores e alunos da rede pública do Estado do

Paraná. Estudos em Avaliação Educacional, Maringá, v. 20, n. 44, p. 1-22, fev./set. 2009. 
ALVES, Jakeline Adriana F.; RESENDE, Gisele Silva Lira de. O papel da avaliação durante o processo de ensino - aprendizagem, na perspectiva do professor do ensino superior. Revista FACISA ON-LINE. Barra do Garças - MT, vol. 03, n. oI, p.13-24, abr., 2014. SUPLEMENTO ESPECIAL - INICIAÇÃO À PESQUISA.

ANAStasiou, L. G. C.; AlveS, L. P. (orgs.). Processos de ensinagem na universidade: pressupostos para as estratégias de trabalho em aula. Joinville, 2003. Tese (dout.) UNIVILLE.

BARBOSA, Flávia Renata Pinto. Avaliação da aprendizagem na formação de professores: estão os futuros professores preparados para avaliar? IX ANPED SUL, 2012. Seminário de $\begin{array}{lllll}\text { Pesquisa em } & \text { Educação } & \text { Região } & \text { Sul. }\end{array}$ http://www.ucs.br/etc/conferencias/index.php/anpedsul/9anpedsul/paper/viewFile/208 $2 / 587$

BRASIL. Parâmetros curriculares nacionais: introdução aos parâmetros curriculares nacionais. Brasília: MEC/ SEF, 1997. 126p. Disponível em < http://portal.mec.gov.br/seb/arquivos/pdf/livrooı.pdf>. Acesso em: 23 fev. 2017.

CARDOSO, Marcélia Amorim.; GOMES, Maria da Conceição Silva. O processo de avaliação e a prática educativa emancipatória: Um estudo sobre a prova como instrumento de avaliação escolar. Cadernos da Pedagogia. São Carlos, ano 9 v. 9 n. ı8, p. 26-42, jan/jun 2016 .

CARMINATTI, Simone Soares Haas.; BORGES, Martha Kaschny. Perspectivas da avaliação da aprendizagem na contemporaneidade. Est. Aval. Educ. São Paulo, v. 23, n. 52, p. I60-I78, maio/ago. 2012. Disponível em: http://www.fcc.org.br/pesquisa/publicacoes/eae/arquivos/1734/1734.pdf. Acesso em: 23 fev. 2017.

CASTANHEIRA, Ana Maria Porto.; CERONI, Mary Rosane. Formação Docente e a Nova Visão da Avaliação Educacional. Estudos em Avaliação Educacional, v. 19, n. 39, jan./abr. 2008. 
CASTRO, Amélia Domingues; CARVAlHO, Ana Maria Pessoa. Ensinar a Ensinar:

Didática para a Escola Fundamental e Média. São Paulo: Editora Thomson, 2006.

CAVALCANTI NETO, Ana Lúcia Gomes; AQUINO, Josefa de Lima F. A avaliação da aprendizagem como um ato amoroso: o que o professor pratica? Educação em Revista, Belo Horizonte, v. 25, n. 2, p. I-7, ago. 2009. Disponível em: . Acesso em: 23 fev. 2017.

CHAVES, S. Avaliação da aprendizagem no ensino superior: realidade, complexidade e possibilidades. In: Reunião anual ANPED, 27 $7^{\underline{a}}$, 2002, Caxambu. Anais... Caxambu: Anped, 2004. p. I-I6.

CHUEIRI, Mary Stela F. Concepções sobre a avaliação escolar. Estudos em Avaliação Educacional, São Paulo, v. 19, n. 39, jan./abr. 2008, v.19, n. 39, p. 49-

64, jan./abr. 2008. Disponível em:

〈http://www.fcc.org.br/pesquisa/publicacoes/eae/arquivos/I418/I4I8.pdf〉. Acessoem: 23 fev. 2017.

COSTA, Jeiffieny da Silva. Docência no ensino superior: professor aulista ou professor pesquisador? Caderno Discente do Instituto Superior de Educação - Ano 2, n. 2 Aparecida de Goiânia - 2008.

ESTEBAN, Maria Tereza. O que sabe quem erra? Reflexões sobre avaliação efracasso escolar. 4. ed. Rio de Janeiro: Editora DP\&A, 2006.

FERNANDES, Domingos. O papel dos professores no desenvolvimento da avaliação para as aprendizagens. VIII Congresso Internacional de Educação. Portugal: Sapiens, 2009.

FERREIRA, J. W. Avaliação da aprendizagem e outros temas do ensinosuperior. Cuiabá: Kcm, 2008. 
FREITAS, Sirley Leite.; COSTA, Michele Gomes Noé da.; MIRANDA, Flavine Assis de. Avaliação Educacional: formas de uso na prática pedagógica. Meta: Avaliação |Rio de Janeiro, v. 6, n. I6, p. 85-98, jan./abr. 2014

FRIAS, Marcos Antônio da Eira e TAKAHASHI, Regina Toshie. Avaliação do processo ensino-aprendizagem: seu significado para o aluno de ensino médio de enfermagem. Disponível em: < http://www.scielo.br/pdf/reeusp/v36n2/v36n2a07.pdf>. Acesso em 23 fev. 2017.

GÓIS, Josilene R. de; BARBOSA, Flavio L. A prova como instrumento incompleto de avaliação da aprendizagem educacional. Revista Científica FACIMED, Cacoal, p. IIO-I22, ago. 2010. Disponível em: . Acesso em: 23 fev. 2017.

, Marlene Correro.; GESSINGER, Rosana Maria.; FREITAS, Ana Lúcia Souza de. (Organizadoras)... [et al.]. Por que falar ainda em avaliação? [recurso eletrônico]. Porto Alegre: EDIPUCRS, 2010. 130 p.

GRILLO, M.C.; LIMA, V.M.R. Especificidades da avaliação que convém conhecer. In: 521 GRILLO, M.C.; GESSINGER, R.M (Org.). Por que ainda falar em avaliação? . Porto Alegre: EDIPUCRS, 2010а. I30p.

HADJI, Charles. A avaliação desmitificada. Porto Alegre: Artmed, 200r. HAMZE, Amélia. Avaliação Escolar. Brasil Escola, 2007. Disponível em: 〈http://www. educador.brasilescola.com/trabalho-docente/avaliacao-escolarhtm〉. Acesso em 23 fev. 2017.

HAYDT, Regina Cazaux. Avaliação do processo ensino-aprendizagem. 6. ed. São Paulo: Ática, 2008.

HOFFMANN, Jussara M. L. Avaliar para promover: As setas do caminho. 14. ed.Porto Alegre: Mediação, 20II.

Avaliação Mediadora: Uma relação dialógica na construção do conhecimento. Disponível em: < http://www.crmariocovas.sp.gov.br/pdf/ideias_22_po5I- 059_c.pdf> 
Acessoem: 23 fev. 2017 .

KRAEMER, Maria Elisabeth Pereira. A avaliação da aprendizagem como processo construtivo de um novo fazer. 20II. Disponível em: < http://www.ufvjm.edu.br/site/educacaoemquimica/files/2010/II/AvaliacaoComoProcesso-de-Construcao.pdf $>$. Acesso em: 23 fev. 2017.

KRASILCHIK, Miriam. Prática de Ensino de Biologia. São Paulo: Editora USP, 4aEd., 2008.

LEITÃO, Inês Achega. Os Diferentes Tipos de Avaliação: Avaliação Formativa e Avaliação Sumativa. Outubro, 2013.

LIMA, Tatiane de Lucena. Avaliação da aprendizagem no ensino superior: contrapontos entre teorias, legislações e exames oficiais. Revista diálogos \& ciências, Ano 16, № 37, Agosto 2016. Disponível em: $<$ http://periodicos.ftc.br/ P. 86

- I03>. Acesso em: 23 fev. 2017.

LIBÂNEO, José Carlos. Didática. 30. reimp. São Paulo: Cortez, 1994. (Coleção Magistério. Série Formação do Professor).

LUCKESI, Cipriano Carlos. Avaliação da aprendizagem escolar: estudos e proposições. 22. ed. São Paulo: Cortez, 20II.

LUCKESI, Cipriano. Faz sentido, no contexto da avaliação, servi-nos do termo "avaliação somativa"? Publicada em 04/o9/2006. Disponível em: http://www.luckesi.com.br/pergunda_e_respostas_questao_II.htm Acesso em $23 \mathrm{fev}$. 2017 .

LUCKESI, Cipriano Carlos. Avaliação da aprendizagem escolar. São Paulo: Cortez: 2011.

MALHEIROS, Bruno Taranto. Metodologia da pesquisa em educação. Rio de 
Janeiro: LTC, 2012.

MORETTO, Vasco Pedro. Prova: Um Momento Privilegiado de Estudo, não um acerto de contas. 8. ed. Rio de Janeiro: Lamparina, 2008.

OLIVEIRA, João Batista Araujo; CHADWICK, Clifton. Aprender e Ensinar. Belo Horizonte: Editora Alfa Educativa: 8a Ed., 2007.

PONTA GROSSA. Secretária Municipal de Educação. Gestão 2001/2004. Diretrizes Curriculares do Ensino Fundamental. Ponta Grossa, PR, 2003.

ROMÃO, José Eustáquio. Avaliação dialógica: Desafio e perspectivos. 9 ed. São Paulo: Cortez, 20II.

RIBAS, M. H. Avaliação formativa: sua importância para o processo ensinoaprendizagem. In: Nadal, B. G. (org). Práticas pedagógicas nos anos iniciais: concepção e ação. Ponta Grossa: Editora UEPG, 2007. p.I47-ı64.

SALINAS, Dino. Prova amanhã! A avaliação entre a teoria e a realidade. PortoAlegre: Artmed, 2004.

SANTANNA, Ilza M. Por que avaliar? Como avaliar? Petrópolis: Vozes, 2010.

SANTOS, Monalize Rigon da; VARELA, Simone. A Avaliação como um Instrumento Diagnóstico da Construção do Conhecimento nas Séries Inicias do Ensino Fundamental. Revista Eletrônica de Educação. Ano I, No. oI, ago. / dez. 2007.

SIBILA, Miriam Cristina C. O erro e a avaliação da aprendizagem: concepção de professor. 2012. 107 f. Dissertação (Mestrado em Educação). Universidade Estadual de Londrina, Londrina, 2012.

SCHERER, Emanuele Amanda.et al. Aprendizagem e Avaliação no Ensino Médio e Superior: Concepções, Práticas e Perspectivas Sociais X Salão de Iniciação Científica - 
PUCRS, 2009.

SOBRINHO, J. D. Avaliação: políticas educacionais e reformas da educação superior. São Paulo: Cortez, 2006.

SOUSA, Georgyna Batista de Carvalho. A eficácia da avaliação qualitativa noprocesso de ensino-aprendizagem. In: Mundo Jovem. Publicação on line da Pontifícia Universidade Católica do Rio Grande do Sul. Porto Alegre, 20 Ir.

Disponível em: . Acesso em 23 fev. 2017.

SOUZA, Lilian Amaral da Silva.; OKÇANA, Battini. A formação por base em competências na educação profissional frente às novas tecnologias. Revista Eletrônica de Educação e Tecnologia do SENAI-SP. 70. v.4, n.8, mar. 2010.

SILVA FILHO, José Amadeu da.; FERREIRA, Celeciano da Silva.; MOREIRA, Régia Maria Gomes. Avaliação educacional: sua importância no processo de aprendizagem do aluno. Campina Grande: REALIZE Editora, 2012.

VILLAS BOAS, Benigna Maria de Freitas. Avaliação formativa e formação de professores: ainda um desafio. Linhas Críticas, Brasília, v. I2, n. 22, p. 75-90, jan./jun. 2006. Disponível em: http://www.proiac.uff.br/sites/default/files/avaliacao_formativa_feedback.pdf $>$. Acesso em: 23 fev. 2017 .

ZANON, Dulcimieri. Aparecida Volante.; FREITAS, Denise. A aula de ciências nas séries iniciais do ensino fundamental: ações que favorecem a sua aprendizagem. Ciências \& Cognição, v.10, p.93-103, 2007. 